\title{
TRIBOLOGICAL BEHAVIOUR OF POLYALPHAOLEFINS: WEAR AND ROLLING CONTACT FATIGUE TESTS
}

\author{
E. Fernández Rico \\ University of Oviedo, Spain. Carretera de Castiello s/n. 33204 Gijón. Asturias. Email: efrico@correo.uniovi.es \\ D. García Cuervo. \\ University of Oviedo, Spain. Carretera de Castiello s/n. 33204 Gijón. Asturias.
}

A. Hernández Battez

University of Oviedo, Spain. Carretera de Castiello s/n. 33204 Gijón. Asturias. Email: antolin@correo.uniovi.es

\section{SUMMARY}

Polyalphaolefin fluids are gaining rapid acceptance as high-performance lubricants and functional fluids because they have certain inherent, and highly desirable, characteristics relative to mineral oils. One of these characteristics is their low toxicity. It combined with excellent viscometrics and lubricity, have made low-viscosity PAO fluids an important component in lubricant formulations.

Typical data found in product specifications for lubricants are the kinematic viscosity and the viscosity index. These values do not give enough information to choose the optimum lubricant for a lubricated contact. In mechanical systems take place rolling, sliding and rolling/sliding contacts, therefore lubricants have to work the best possible in these operation conditions.

In this study are experimentally determined the $\mathrm{L}_{50}, \mathrm{~L}_{10}$ and Weibull's slope $(\alpha)$ of polyalphaolefins with two different viscosities. This test was made on a four-ball machine (Stanhope Seta). Wear test also was made on a four-ball tester (Roxana) in order to measure the wear scar diameter (WSD), and the flash temperature parameter (FTP). Lubricants were identified through infrared spectroscopy, and ball's pittings were observed with SEM.

Keywords: Polyalphaolefins, rolling contact fatigue, wear, SEM, four-ball machine.

\section{INTRODUCTION}

The polyalphaolefin (PAO) fluids are the first and foremost synthetic hydrocarbons in commercial importance [1]. This commercial importance is due to their wide operational temperature range, good viscometrics (high viscosity index), thermal stability, hydrolytic stability, compatibility with mineral oils, low toxicity, good to moderate relative biodegradability, etc. [2].

Typical data found in product specifications for lubricants are the kinematic viscosity and the viscosity index. These values do not give enough information to choose the optimum lubricant for a lubricated contact [3]. In mec7hanical systems take place rolling, sliding and rolling/sliding contacts, therefore lubricants have to work the best possible in these operation conditions. In order to avoid wear, it is necessary to keep the lubricant film thick enough to prevent any contact between the surfaces. Friction should be minimised in order to obtain as high efficiency as possible and pressure peaks should be as small as possible to avoid large sub-surface stresses and thus avoid pitting fatigue [3]. An equation that describe the influence of some parameters in lubricant film is the Hamrock-Dowson one (Equation 1) for elliptical conjunctions.

$$
\begin{aligned}
& h_{c}=2.69 u^{0.67} \cdot \eta_{0}{ }^{0.67} \cdot E^{-0.073} \cdot \alpha^{0.53} . \\
& w^{-0.067} \cdot R_{x}{ }^{0.464}\left(1-0.61 e^{-0.73 k}\right)
\end{aligned}
$$

This paper present the results of current studies about the general tribological behaviour of polyalphaolefins. Measurements of wear scar diameter, rolling contact fatigue, flash temperature parameter (FTP) were made. Lubricants were identified through infrared spectroscopy, and ball's pittings were observed with SEM.

\section{EXPERIMENTAL}

\subsection{Apparatus}

The four ball friction apparatus used in this study was a Falex Roxana machine and tests were made using the ASTM standard D 4172-88. The rolling contact fatigue tests took place in a Stanhope Seta four ball machine and the standard used was the IP-300/82. The ball test material was AISI 52100 steel, $12.7 \mathrm{~mm}$. in diameter, with a hardness of about 65 HRC and its chemical composition can be observed on Table 1 . 


\begin{tabular}{|c|c|}
\hline \multicolumn{2}{|c|}{ Chemical Composition (wt. \%) } \\
\hline $\mathrm{C}$ & $0.98-1.1$ \\
\hline $\mathrm{Si}$ & $0.15-0.30$ \\
\hline $\mathrm{Mn}$ & $0.25-0.45$ \\
\hline $\mathrm{P}$ & 0.025 \\
\hline $\mathrm{S}$ & 0.025 \\
\hline $\mathrm{Cr}$ & $1.30-1.60$ \\
\hline
\end{tabular}

Table 1: Chemical Composition (wt. \%) of the AISI 52100 steel ball material.

\subsection{Oil samples}

The viscosities of polyalphaolefins used in this study are shown in Table 2.

\begin{tabular}{|c|c|c|}
\hline \multirow{2}{*}{ Code } & \multicolumn{2}{|c|}{ Viscosity $(\mathrm{cSt})$} \\
\cline { 2 - 3 } & $40^{\circ} \mathrm{C}$ & $100^{\circ} \mathrm{C}$ \\
\hline PAO 6 & 31.0 & 5.90 \\
\hline PAO X & 55.0 & 8.70 \\
\hline
\end{tabular}

Table 2: Viscosities of Oils.

Both oil samples were identified through infrared spectroscopy and the spectrum were the same of the spectra given by Sadtler Research Laboratories, Inc., for polyolefins. The spectrometer used was the FT-IR PARAGON 1000 of PERKIN ELMER.

\subsection{Calculated parameters and test conditions}

The calculated parameters in the wear tests were the scar wear diameter (WSD) and the flash temperature parameter (FTP). The WSD was measured using a microscope according to ASTM 4172-88. The FTP was calculated with the formula:

$\mathrm{FTP}=W / d^{1.4}$

where $W$ is the load in kilograms, and $d$ is the mean wear scar diameter (WSD) in millimetres at this load. This single number express the critical flash temperature above which a given lubricant will fail under given conditions.

The calculated parameters in the rolling contact fatigue tests were the $\mathrm{L}_{10}, \mathrm{~L}_{50}$, and Weibull's slope $(\alpha)$. The behaviour load-fatigue life was determined through tests with three different loads (from 500 to $700 \mathrm{~kg}$.) and the same velocity $\left(1470 \mathrm{rev} \cdot \mathrm{min}^{-1}\right)$. The test runs were finished when pitting occurred in any ball. The results were processed using the Weibull's theory.

Wear scar, worn surfaces and pitting fatigue were observed using a scanning electronic microscope (SEM) after test runs.

\section{RESULTS AND DISCUSSION}

\subsection{Rolling contact fatigue}

The results of rolling contact fatigue test can be observed in Figure 1. The rolling contact fatigue life decrease with the increase of load. If the HamrockDowson equation is checked, the higher load the thinner oil film thickness in the contact and the asperities interaction is higher too. These phenomena increase the stress below the contact and pitting occur easier.

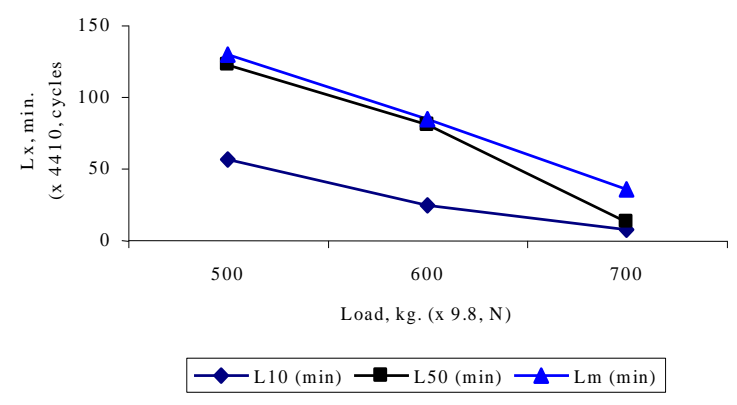

Figure 1: Results of Rolling Contact Fatigue Test in PAO 6.

In the Figure 2 appear the temperature behaviour during the rolling contact fatigue test, it is appreciated that the higher load the higher test temperature. This temperature increase due to load increase, diminish the oil viscosity and the film thickness become thinner too.

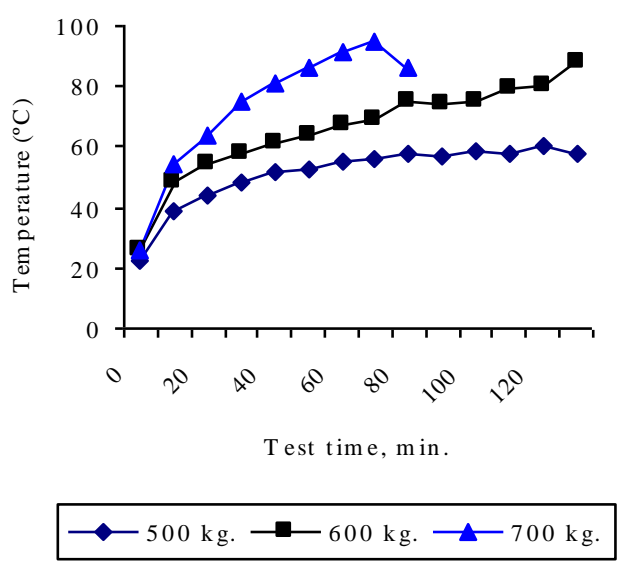

Figure 2: Temperature Behaviour of Rolling Contact Fatigue Test in PAO 6.

The PAO X's results in rolling contact fatigue life and temperature behaviour are, in general, the same of PAO 6, Figures 3 and 4.

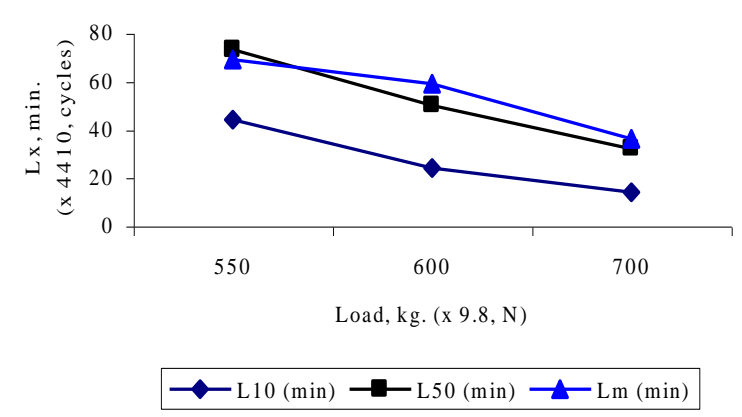

Figure 3: Results of Rolling Contact Fatigue Test in PAOX. 


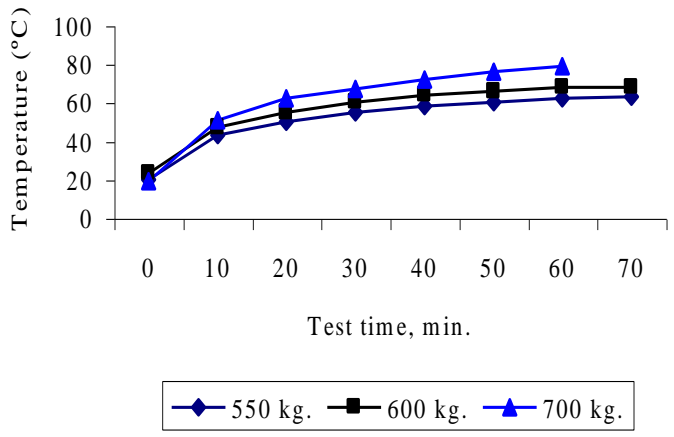

Figure 4: Temperature Behaviour of Rolling Contact Fatigue Test in PAOX.

If we observed the $\mathrm{L}_{10}$ and $\mathrm{L}_{50}$ behaviour of PAO 6 and $\mathrm{PAO} \mathrm{X}$ on the tested load range, Figures 5 and 6 , the $\mathrm{L}_{10}$ of PAO X is always better but the $\mathrm{L}_{50}$ is only better for loads higher to $650 \mathrm{~kg}$. This phenomenon can be attributed to the dynamic process in the conjunctions. The temperature in the test of $700 \mathrm{~kg}$. was always higher in PAO 6, Figure 7, that situation did thinner the film thickness and higher the asperities interactions and sub-surface stresses and thus a lower rolling contact fatigue life. The temperature in the test of 600 $\mathrm{kg}$. was lower in PAO X until a test time of 20 minutes, which coincide approximately with the $\mathrm{L}_{10}$ of both oils, after that time the temperature of PAO X become higher and the viscosity of fluid decreased, as well as the film thickness, and the rolling contact fatigue life to make worse, Figure 8.
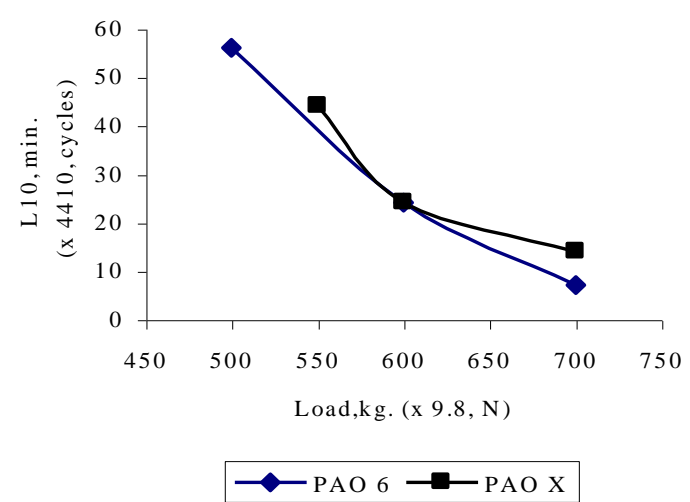

Figure 5: Comparison of $L_{10}$ of PAO 6 and PAOX.

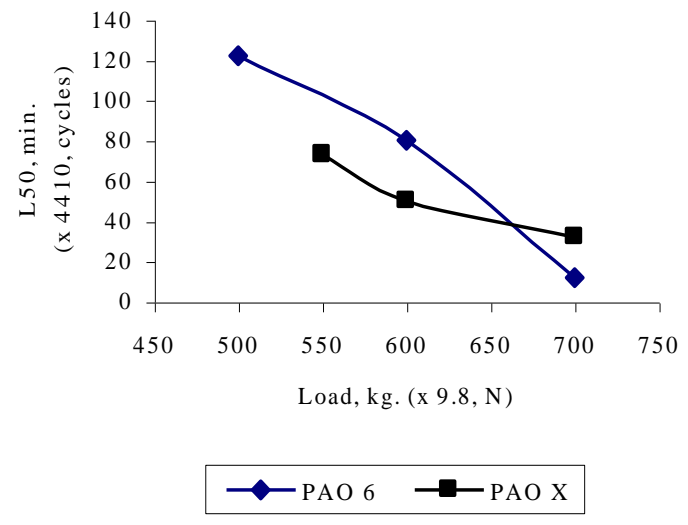

Figure 6: Comparison of $L_{50}$ of PAO 6 and PAOX.

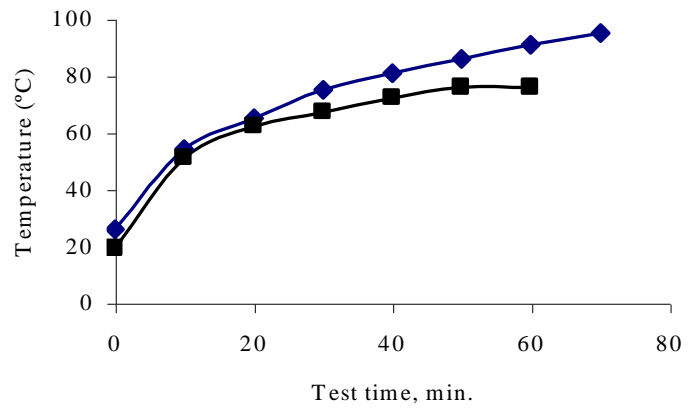

$\sim$ PAO $6 \multimap$ PAO $\mathrm{x}$

Figure 7: Temperature behaviour in $700 \mathrm{~kg}$. test.

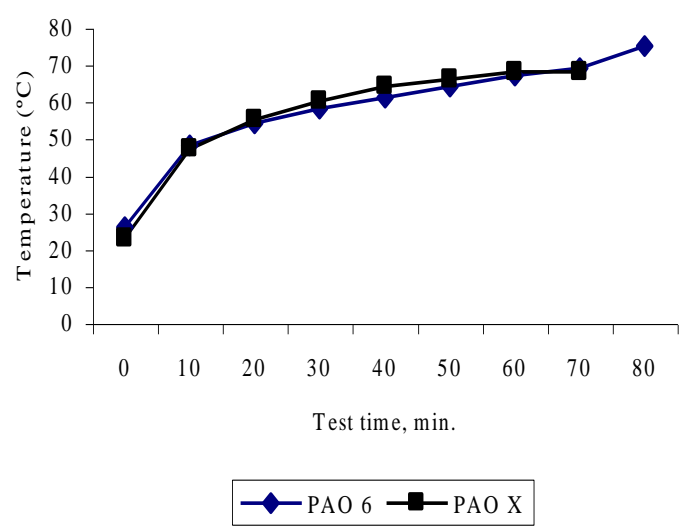

Figure 8: Temperature behaviour in $600 \mathrm{~kg}$. test.

The Weibull's slope $(\alpha)$ for each fatigue test appear on Table 3.

\begin{tabular}{|c|c|c|c|c|}
\hline \multirow{2}{*}{ Oils } & \multicolumn{4}{|c|}{ Loads (kg.) } \\
\cline { 2 - 5 } & 500 & 550 & 600 & 700 \\
\hline PAO 6 & 2.47 & - & 1.56 & 3.49 \\
\hline PAO X & - & 3.72 & 2.57 & 2.27 \\
\hline
\end{tabular}

Table 3: Weibull's slope $(\alpha)$

3.2 Wear preventive characteristics and Flash Temperature Parameter of oils.

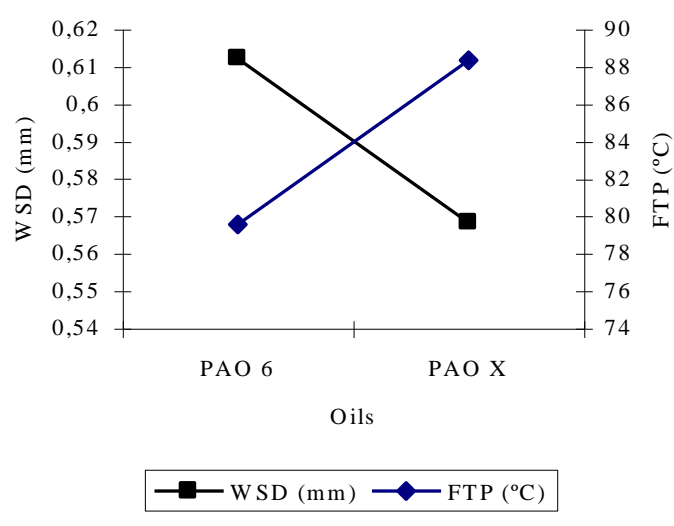

Figure 9: WSD and FTP of PAO 6 and PAOX.

Figure 9 shows how the higher viscosity the lower WSD and the higher FTP. Once again when the viscosity is 
increased the oil film thickness is higher and the WSD decrease. That is why the FTP is higher too, however a friction test should be done in order to know if we are saving energy too.

\subsection{Wear worn surface characteristics.}

The appearance of pitting on test balls are observed on Figures 10 y 11.
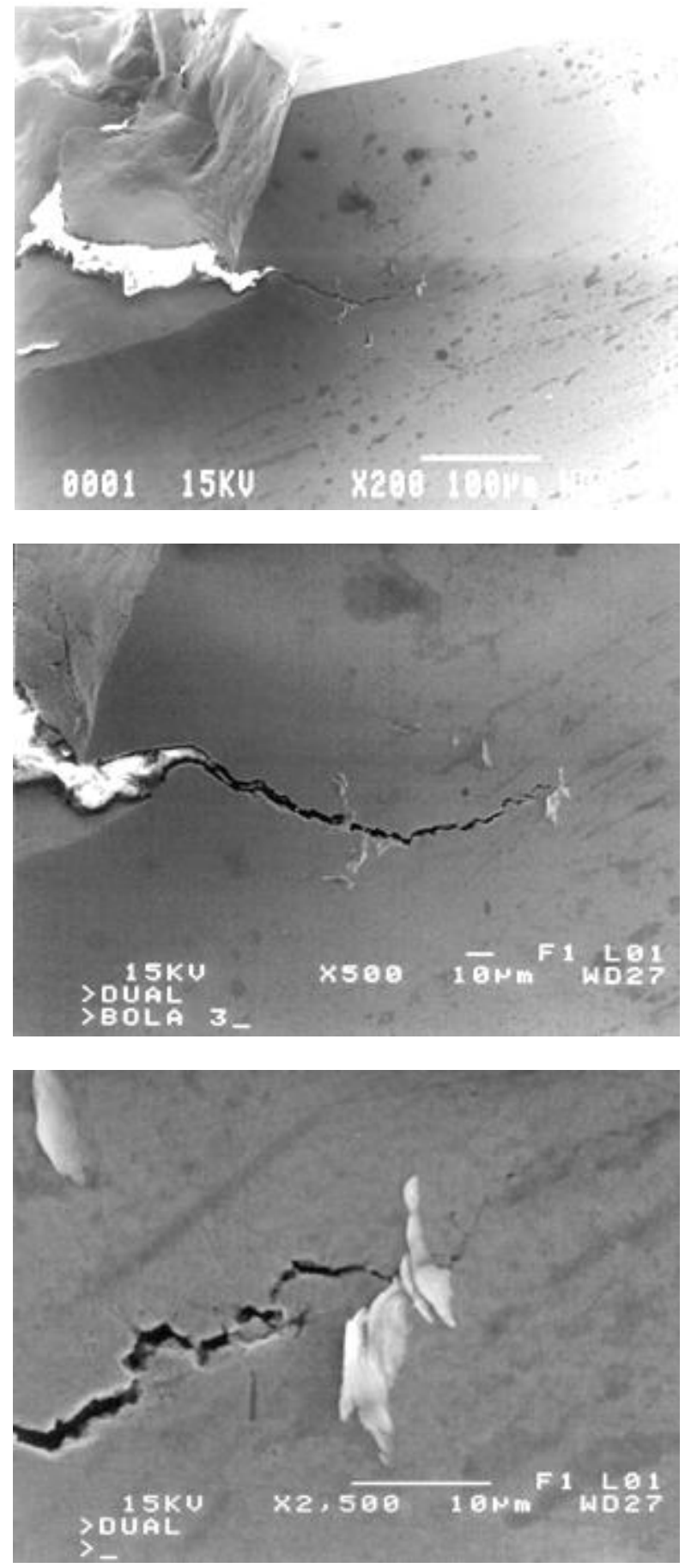

Figure 10: Micrographs showing pitting appearance on a test ball (PAO 6, $600 \mathrm{~kg} ., 58 \mathrm{~min}$.) .
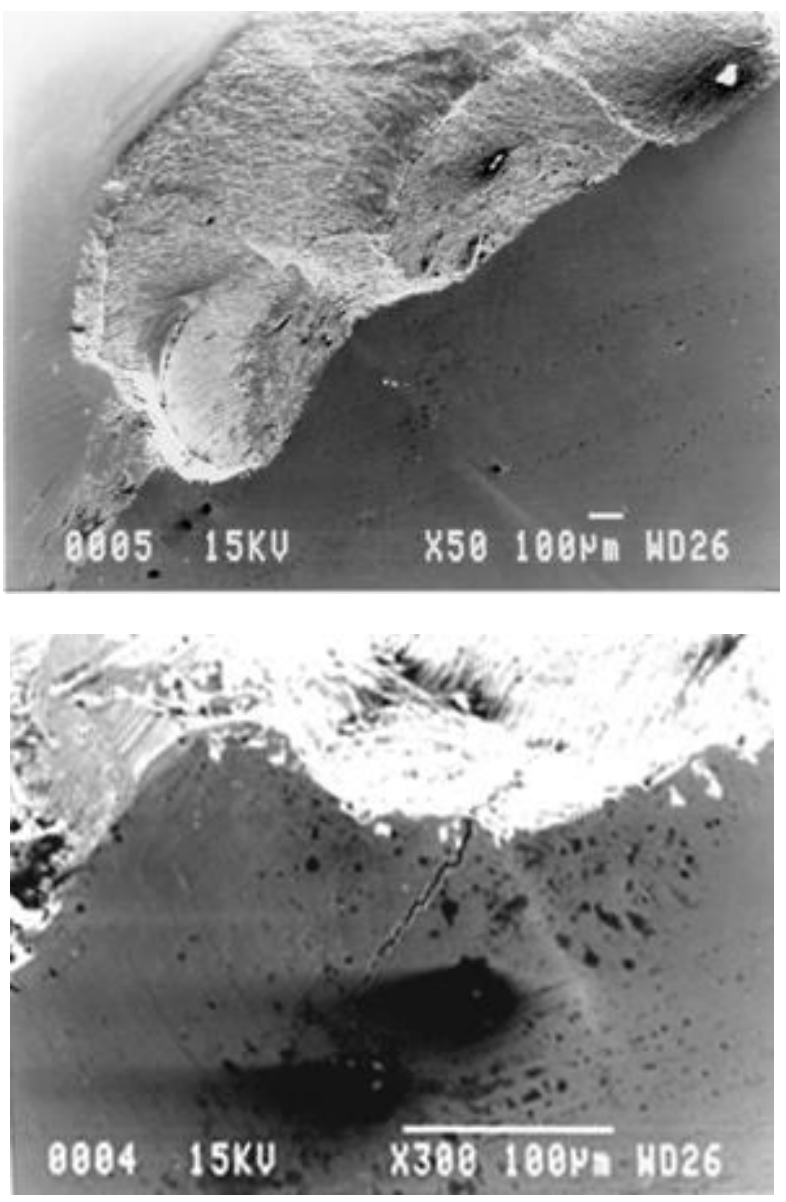

Figure 11: Micrographs showing pitting appearance on a test ball (PAO X, $600 \mathrm{~kg} ., 61 \mathrm{~min}$.).

The prime cause of contact fatigue is the high stresses generated by Hertzian contact. As is the case with other forms of fatigue, the three stages of initiation, propagation and fracture are identified. In the initiation stage is originated by a small crack from either a subsurface inclusion or at the surface from wearing contact between the two rolling bodies. Initiation is strongly correlated with shear stress and most crack initiation sites from subsurface inclusions are located close to the subsurface maximum of shear stress for Hertzian contact. The next stage is crack propagation where more rapid growth of the crack occurs leading to the formation of what is in fundamental terms a wear particle. The final stage is fracture where the crack is large enough to allow detachment of the wear particle. Once the wear particle is detached, the rolling contact vibrates since one of the contacting bodies no longer has an accurately circular profile and if rolling speed is high, considerable noise is generated [4]. This phenomenon can be observed on rolling fatigue test (IP 300). Contact fatigue occurs in both lubricated and unlubricated situations but the presence of oil does modify the mechanisms involved. Any oil present inside a rolling contact is subjected to very high pressures of $1 \mathrm{GPa}$ or more. This high pressure enables the oil to separate the contacting surfaces, suppress the surface mode of contact fatigue and thereby prolong the working life of the rolling materials. The same high pressure does however accelerate crack growth by pressurising the 
space between the crack surfaces. This theory is the same that Jin and Kang stated [5].

If the Figures above are observed, cracks's depth are found around $150 \mu \mathrm{m}$. From theory of Hertz it can be calculated the depth which maximum stress appear. Wang [6] did this calculus for a four-ball machine and for a load of $600 \mathrm{~kg}$ obtained the following results:

$$
\begin{aligned}
\mathrm{p}_{\max } & =8709 \mathrm{MPa} \text { (maximum normal stress). } \\
\tau_{\max } & =2612 \mathrm{MPa} \text { (maximum shear stress). } \\
\mathbf{z} & =\mathbf{1 3 9} \boldsymbol{\mu \mathbf { m }} \text { (depth of maximum shear stress). }
\end{aligned}
$$

\section{CONCLUSIONS}

From the results it can be concluded that:

1. The higher load the higher temperature and lower rolling contact fatigue life.

2. The viscosity has an important influence on rolling contact fatigue life but the temperature should not be despised.

3. In the wear tests the results were better when the viscosity was increased.

4. In oils belong to the same family properties as pressure-viscosity coefficient, temperature-viscosity coefficient, compressibility, thermal conductivity and heat capacity per unit volume are approximately equals. In this case the viscosity can become in the principal property.

5. The theory of Hertz is verified for both oils.

\section{REFERENCES}

[1] Shubkin, R. L. Polyalphaolefins. In Synthetic Lubricants and High-Performance Functional Fluids. Ed. 1993, Marcel Dekker. New York, pp. 1-40.

[2] Totten, George E. Handbook of Hydraulic Fluid Technology. Ed. 2000, Marcel Dekker. New York, pp. 827.

[3] Larsson, R., Kassfeldt. Base fluid parameters for EHL and friction calculations and their influence on lubrication capability. In Proceeding of 12th International Colloquium Tribology 2000 - Plus. Esslingen 2000. 1525-1536.

[4] William Batchelor, Andrew; Nee Lam, Loh; Chandrasekaran, Margam. Materials Degradation and its Control by Surface Engineering. Imperial College Press, 1999. p. 58.

[5] Jin, X. Z.; Kang, N. Z. A Study on Rolling Bearing Contact Fatigue Failure by Macro-Observation and Micro-Analysis. Hangzhou Bearing Test and Research Center.

[6] Wang, Yinglong; Fernández, J.E.; Cuervo, D.G. Rolling-contact fatigue lives of steel AISI 52100 balls with eight mineral and synthetic lubricants. Wear 196 (1996) 110-119. 